\title{
Çözüm Önerisinin İtici Görülüp Görülmemesi Kürt Sorununu Kabul Etmeyi Etkiliyor mu?
}

\author{
Arş. Gör. Fatih BAYRAK* \\ Başkent Üniversitesi, Fen Edebiyat Fakültesi, Psikoloji Bölümü, Ankara / Türkiye, \\ fatihbayrak@baskent.edu.tr, ORCID: 0000-0001-6350-6234 \\ Dr. Öğr. Üyesi Sinan ALPER \\ Yaşar Üniversitesi, İnsan ve Toplum Bilimleri Fakültesi, Psikoloji Bölümü, İzmir / Türkiye, \\ sinan.alper@yasar.edu.tr, ORCID: 0000-0002-9051-0690 \\ Dr. Öğr. Üyesi Onurcan YILMAZ
}

Kadir Has Üniversitesi, İktisadi, İdari ve Sosyal Bilimler Fakültesi, Psikoloji Bölümü, İstanbul / Türkiye, onurcan.yilmaz@khas.edu.tr, ORCID: 0000-0002-6094-7162

\section{$\ddot{O} z$}

Sonuçları tüm insanları ve çevreyi etkilemesine rağmen bilimsel olarak gerçekliği tespit edilmiş küresel ısınma gibi sorunların varlığı insanların bir kısmı tarafından reddedilmektedir. Bu konudaki alanyazına göre bilimsel sorunların varlığını reddetme ideolojik değerlendirmelerin etkisiyle şekillenebilmektedir. Cambpell ve Kay (2014) tarafından gerçekleştirilen yeni bir araştırmaya göre ise bir sorunun çözümüne yönelik öne sürülen çözüm önerilerinin bireyler tarafindan itici olarak görülmesi, o sorunun varlığını reddetmelerinin gerekçesi olabilir. Bu çalışmada küresel ısınma gibi bilimsel gerçeklerin reddedilmesi çerçevesinde yapılan çalışmalarda ortaya çıkan çözüm hoşnutsuzluğu (solution aversion) hipotezi, tanımı ve nasıl çözüleceği Türkiye’de hâlen

* Sorumlu Yazar. Tel: +90 5546305169

Makale Tarih Bilgisi. Gönderim: 05.05.2019, Kabûl: 23.11.2019, Basım: Haziran, 2021

(C) 2021. Kalem Eğitim ve Sağlık Hizmetleri Vakfı. Bütün Hakları Saklıdır. ISSN: 2146-5606, e-ISSN: 2687-6574. 
tartışmalı bir konu olan Kürt sorunu bağlamında ele alınmıştır. Katılımcılara Kürt sorununa yönelik iki farklı çözüm önerisi sunulmuş, ardından Kürt sorununun varlığını kabul etme düzeyleri ölçülmüştür. Analiz sonuçlarına göre itici olarak görülen çözüm önerisine maruz kalmak Kürt sorununun varlığını reddetmeyi etkilememiştir. Ayrıca daha solcu bireylerin Kürt sorununun varlığını daha fazla kabul ettikleri ancak milliyetçilik ve dindarlık düzeylerinin sorunu kabul etme ile ilişkisinin olmadığı görülmüştür. Elde edilen sonuçlar, Kürt sorununun dinamikleri ve ilgili alanyazın çerçevesinde tartışılmış, gelecekte yapılacak bilimsel çalışmalar ve politikalar için öneriler sunulmuştur.

Anahtar Kelimeler: Çatışma; Çözüm; Çözüm hoşnutsuzluğu; Gruplar arası ilişkiler; Kürt sorunu.

\title{
Does Perception of Solution Proposal as Aversive Affect the Acknowledgment of Kurdish Question?
}

\begin{abstract}
Although environmental problems such as global warming have been scientifically determined and affect all people, some people reject the existence of these problems. According to the literature, denials of these problems are generally shaped by the influence of ideological evaluations. In more recent study Campbell and Kay (2014) argued that denial of the problem may be caused by an aversive perception of the proposed solution. In this study, solution aversion hypothesis, which was generated to understand the denial of scientific facts was examined in the context of Kurdish Question which is still a controversial issue in terms of its solution and definition in Turkey. Two different solution suggestions (aversive and sympathetic) were presented to the participants, and the level of acceptance of the Kurdish Question was measured. Results showed that exposure to the aversive solution did not affect the acceptance of the Kurdish Question. Moreover, it was observed that the left-wing individuals accepted the existence of the Kurdish Question more than right-wings but the levels of nationalism and religiosity were not related to acceptance of the problem. The findings and limitations of the study were discussed within the framework of the dynamics of the Kurdish Question and related literature. Suggestions for future studies and policies were presented.
\end{abstract}

Keywords: Conflict; Intergroup relations; Solution; Solution aversion; Kurdish question. 


\section{Extended Summary}

\section{Purpose}

Throughout history, Turkey has always been a country hosting individuals from many different cultures and ethnic identities. Today, the largest ethnic minority group is the Kurds with about $20 \%$ of the general population (Ergin, 2014; Konda, 2011; Y1ld1z, 2007). Although the Kurdish Question is quite important in terms of its negative results, research on this issue is very limited in Turkish psychology literature (see also Balaban, 2013; Bayad, 2015; Baysu, Coşkan and Duman, 2018; Cingöz-Ulu, 2008; Çelebi, Verkuyten, Köse and Maliepaard, 2014; Göregenli, 2010; Y1lmaz, Cesur and Bayad, 2018).

There are several studies that have been conducted on the denial of the scientific facts such as climate change (Leiserowitz, Maibach, Roser-Renouf, Feinberg and Rosenthal, 2015; Tranter and Booth, 2015), global warming (McCright and Dunlap, 2011), and the effects of ideologies (Hamilton, Hartter and Saito, 2015; Jessani and Harris, 2018) on these attitudes. Studies have shown that right-wings tend to reject the existence of the problem (Gifford and Nilsson, 2014), underestimate the importance of it (Feygina, Jost and Goldsmith, 2010) while the left-wings are less likely to exhibit these tendencies (Gifford and Nilsson, 2014; Hamilton, Hartter and Saito, 2015).

Campbell and Kay (2014) conducted a series of studies based on the literature mentioned above (McCright and Dunlap, 2011; Pew Research Center, 2010) and focused on the effects of the solution type on accepting a problem. They found that even though the problem concerns all people in the world and is scientifically proven to exist, perceiving the solution type aversive or not makes a significant difference in the acceptance of the problem. In addition, findings showed that these reactions are shaped by solution type which is consistent with the ideology.

In this study, based on the results of Campbell and Kay (2014), we conducted an experiment focused on the Kurdish Question. To investigate the possible effects of the solution types on the acceptance of the Kurdish Question's existence, we targeted solutions that generally seemed to be aversive (e.g., education in the mother tongue, autonomy) and sympathetic (e.g., merging in the Turkish identity) in the society. Then we examined whether the individuals accept the existence of the Kurdish Question due to the solution type. 


\section{Method}

A total of 245 ( 210 women; $\left.\mathrm{M}_{\mathrm{age}}=20.73, \mathrm{SD}=1.58\right)$ undergraduate students from Baskent University and Middle East Technical University participated in the study. In the first part of the study, participants were randomly divided into three groups. In the first group $(\mathrm{n}=81)$, an aversive solution type, and in the second group $(n=82)$ a sympathetic solution type was proposed. The third group ( $\mathrm{n}=82$ ) was used as the control group. After the manipulations, participants in all groups answered the following question: "In your personal opinion, is there a Kurdish problem in Turkey? Please provide your own answer using the answer format below." In addition, participants responded to various questions about their gender, age, ideology, nationalism, religiousness, and ethnicity with one item. Before the data was collected, the hypothesis, study design, and analysis plan were recorded with preregistration and the data and measurement tools were also shared online. ${ }^{1}$

\section{Results}

Bivariate Pearson correlation analyses were conducted to examine the relationships between the study variables (see Table 1). Ideological orientation was observed to have significant positive correlations with nationalism $(\mathrm{r}=.37, p<.001)$ and religiousness $(\mathrm{r}=.58, p<.001)$. In addition, nationalism had a significant positive correlation with religiousness $(\mathrm{r}=.54, p<.001)$. An ANOVA was conducted to compare the effect of solution types on acceptance of Kurdish Question in aversive, sympathetic and control groups. There was no significant effect of the aversive $(\mathrm{M}=4.67, \mathrm{SD}=1.90)$, the sympathetic $(\mathrm{M}=4.62, \mathrm{SD}=1.80)$, and the control $(\mathrm{M}=4.32, \mathrm{SD}=1.91)$ groups on acceptance of Kurdish Question, $\mathrm{F}(2.242)=.85, p=.431$. Since manipulation was not effective, all conditions were combined in a separate analysis which showed that participants with a left-wing ideology accepted the existence of the Kurdish Question more than those with a right-wing ideology, $\mathrm{r}(243)=-.13$, $p=.046$. However, nationalism, $\mathrm{r}(243)=.06, p=.343$ and religiousness, $\mathrm{r}(243)=-.04, p=.561$, were not found to be related to the acceptance of the Kurdish Question.

\section{Discussion}

According to the findings, the different solution proposals (aversive and

\footnotetext{
1 Preregistration form (https://osf.io/jye8z/register/565fb3678c5e4a66b5582f67), data and measurement tools can be accessed at the project page (https://osf.io/3gnx9/?view_only=19fd18778cb34085affdfd4024321a76).
} 
sympathetic) have no effect on accepting the Kurdish Question. As for ideological orientations, it was found that the left-wings were more likely to accept the Kurdish Question. In addition, nationalism and religiousness levels did not have a significant effect on this relationship. In other words, the type of solution (aversive or sympathetic) did not matter in terms of the rejection of the Kurdish Question.

The finding that people with a left-wing ideology (assume to have more liberal ideas than people with a left-wing ideology in Turkey) accepted the Kurdish Question rather than right-wings are consistent with the studies on the denial of scientific facts (Dunlap, McCright and Yarosh, 2016; Fisher, Fitzgerald and Poortinga, 2018; Gifford and Nilsson, 2014; Hamilton, Hartter and Saito, 2015). However, the level of nationalism and religiousness having no significant effect on the acceptance of the problem is an interesting finding of the current study. These results differ from the literature of political psychology, which is mostly based on left-right distinction in Western samples (e.g., Jost, Nosek and Gosling, 2008).

\section{Conclusion}

Although studies have been carried out in many different fields (economics, politics, sociology, etc.) on the Kurdish Question, the empirical research investigating the possible effects of psychological variables is rather scarce. The exploration of psychological factors that feed different perspectives towards the Kurdish Question will provide important information for determining the policies and increasing the social welfare. The present study not only contributes to the literature but also paves the way for future studies. In addition, it provides an informative resource to policy makers who can play a role in a possible future solution.

\section{Giriş}

Türkiye, tarihsel süreç içerisinde pek çok farklı kültürden ve etnik gruptan bireylerin yaşamını sürdürdüğü oldukça çeşitlilik arz eden bir coğrafya olagelmiştir. Bugün ülke sınırları içerisindeki en büyük etnik azınlık grubu ise genel nüfusun yaklaşık \%20'si ile Kürtler oluşturmaktadır (Ergin, 2014; Konda, 2011; Yıldız, 2007). Kürt sorunu için farklı siyasî bakış açıları ve kuramsal yaklaşımlar tarafindan bugüne kadar birçok farklı tanımlama yapılmış olsa da sonuçları açısından düşünüldügünde Kürt sorununun gündelik yaşamdan ekonomiye varıncaya dek oldukça geniş bir etki alanına sahip olduğu gö- 
rülmektedir. Kürt sorunu, kökenleri daha eskiye, Osmanlı dönemi ve cumhuriyetin kuruluş dönemlerine dek dayanan (Ergil, 2000) fakat 1980'lerden itibaren yoğunlaşan PKK ile Türkiye Cumhuriyeti arasındaki çatışmalar sonucunda resmi rakamlara göre 30 yıl içerisinde 35.000 'in üzerinde insanın hayatını kaybetmesine ve 400.000'e yakın insanın yaşam alanlarını terk etmesine sebep olmuş önemli bir olgudur (Arkonaç, Tekdemir ve Çoker, 2012; Kirişçi ve Winrow, 2011; Meclis Araştırması Komisyonu Raporu, 2013; Yeğen, 2009). Bu yıkıcı sonuçları itibariyle Türkiye'de Kürtler ve Türkler arasındaki ayrım daha da derinleşmiş ve birbirlerine yönelik olumsuz tutumları katılaşmıştır (Keyman, 2012; Yılmaz, Bayad ve Cesur, 2018). Konda'nın (2011) araştırmasına göre toplumun \%8'i Kürt sorunu bağlamındaki çatışmalardan doğrudan fiziksel olarak zarar görmüştür. Araştırmaya göre yaşanan çatışmalara paralel olarak, toplumda gerilimi arttırıcı ideolojiler de yaygınlaşmış, bireylerin birbirlerine yönelik tutumlarında olumsuz yönde artış gözlenmiştir. Örneğin, araştırmaya katılan Türklerin yarısının Kürtlerin ise dörtte birinin diğer etnik kökenden bireyleri kendilerine eş ya da komşu olarak istemedikleri tespit edilmiştir. Bugüne kadar Kürt sorununun çözümüne yönelik farklı tarihsel dönemlerde, çeşitli yönleri açısından birbirinden farklı çözüm önerileri ortaya atılmıştır (Kirişçi, 2011; Yeğen, 2012). Siyasî parti kapatmaları (Villelas, 2011), politik reformlar (Kirişçi, 2011), ateşkes görüşmeleri, olağanüstü hâl ilanları ve açılım süreci (Yeğen, 2012; Yıldız, 2012) gibi farklı siyasî ve askerî yöntemlerle soruna yönelik müdahalelerde bulunulmuştur. Fakat bu çabaların hiçbiri kalıcı bir çözümü beraberinde getirecek çıktılar ortaya koyamamıştır.

Kamuoyunda Kürt sorununun tanımı üzerine tam olarak bir fikir birliği bulunmamakta ve sorunun kökenleri farklı siyasî görüşlere sahip insanlar tarafından farklı biçimlerde tarif edilmektedir (Metropoll, 2013; Seta ve Pollmark, 2009; Uluğ ve Cohrs, 2016). Örneğin, bir perspektife göre Kürt sorunu diye bir şey yoktur ve Kürtler aslında Türkiye'de yaşayan diğer etnik kökenden yurttaşlarla aynı haklara sahiptir. Öte yandan henüz sorunun çözüm yöntemi konusunda da tam olarak bir uzlaşı sağlanamamıştır (Metropoll, 2012; Uluğ ve Cohrs, 2017; Yıldız, 2012). Konda (2011) tarafından gerçekleştirilen bir saha çalışmasına göre Türkiye'de yaşayan bireylerin yarısı Kürt sorununun reformlar ve ekonomik düzenlemeler ile çözülebileceğini düşünürken azımsanamayacak bir kısmı ise yalnızca askerî güç ile çözülebileceğini düşünmektedir. Benzer başka bir araştırmada (Metropoll, 2013) ise Türkiye'de yaşayan 
bireylerin \%66's1 Kürt sorununun çözümünde siyasî atılımların etkili olacağını dile getirirken \%33'ü silahlı mücadelenin sorunu çözebileceğini düşünmektedir. Öte yandan Kürt sorunu bağlamında sıkça gündeme gelen anadilde eğitim talebi katılımcıların \%53'ü tarafindan reddedilmektedir. Buna ek olarak, birçok araştırmada Kürt sorununa ilişkin çözüm önerilerine ve Kürtlerin taleplerine karşı toplumda ciddi tepkilerin ortaya çıktığı görülmektedir (Dixon ve Ergin, 2010; Günes, 2012; Keyman, 2012; Konda, 2011). Böylece Kürt sorununa yönelik çeşitli çözüm önerilerine verilen tepkiler aracılı̆̆ıyla Kürtlere yönelik ayrımcı tutumların daha da körüklendiği düşünülmektedir (Günes, 2012; Saraçoğlu, 2009).

Türkçe psikoloji alanyazınında Kürt sorunu bağlamındaki araştırmaların oldukça sınırlı düzeyde olduğu, araştırmaların çoğuna Kürtlerin genellikle Kürt sorununun içeriğinden bağımsız olarak yalnızca farklı bir örneklem grubu olarak dâhil edildiği görülmektedir (Göregenli, 2010; ancak geçmiş bazı çalışmalar için bakınız Balaban, 2013; Bayad, 2015; Baysu, Coşkan ve Duman, 2018; Cingöz-Ulu, 2008; Yılmaz, Cesur ve Bayad, 2018; Çelebi, Verkuyten, Köse ve Maliepaard, 2014). Bunun yanı sıra, gerçekleştirilmiş olan sınırlı sayıdaki araştırmalarda, milliyetçiliğin Kürtlere yönelik olumsuz tutumları tetiklediği (Çelik, 2016; Yılmaz, Cesur ve Bayad, 2018), bir iç grup olarak Türk kimliğiyle yüksek düzeyde özdeşim kurmanın önyarg1 ve ayrımc1lıkla ilişkili olduğu, sosyal baskınlık yöneliminin Kürtlere yönelik önyarg1ları yordadığ (Balaban, 2013; Y1lmaz, Cesur ve Bayad, 2018) ve etnik kimliğiyle özdeşleşme düzeyi daha fazla olanların olası kaynak paylaşımı durumlarında daha fazla kendi gruplarını kayırdığ 1 (Çoksan, 2016) tespit edilmiştir.

Alanyazında özellikle son yirmi yıl içerisinde bireylerin iklim değişikliği (Leiserowitz ve ark., 2015; Tranter ve Booth, 2015), küresel 1sınma (McCright ve Dunlap, 2011), aşılar ve genetiği değiştirilmiş organizmalar (Hamilton, 2015) gibi bilimsel gerçeklerle ilişkili sorunların varlığına inanmamaları ve ideolojilerin bu tutuma yön veren etkileri (Hamilton, Hartter ve Saito, 2015; Jessani ve Harris, 2018; McCright ve Dunlap, 2010) üzerine birçok çalışma yapılmıştır. Bilimsel otoritelerce bir sorun hakkında net olarak fikir birliğine varılmış olsa da toplumların farklı kesimlerinde özellikle farklı ideolojik kampların üyeleri arasında bu sorunun varlığını kabul etmeye ilişkin birbiriyle çatışan görüşlerin olduğu görülmüştür (Druckman ve Mcgrath, 2019). Araştırmalarda insanların sorunun varlığını reddedici tepkilerinin be- 
lirsizliğe tahammülsüzlük (Jessani ve Harris, 2018), adil dünya inancı (Clayton, Koehn ve Grover, 2013; Feinberg ve Willer, 2011), sistemi meşrulaştırma düzeyi (Feygina, Jost ve Goldsmith, 2010; Fritsche, Cohrs, Kessler ve Bauer, 2012) ve sosyal baskınlık yönelimi (Carrus, Panno ve Leone, 2018; Häkkinen ve Akrami, 2014) gibi sosyal psikolojik değişkenlerle ilişkili olduğu tespit edilmiştir. Buna paralel olarak bireylerin ideolojik yönelimlerinin (sol-sağ) bilimsel olarak ispat edilmiş sorunların varlığını reddetme davranışını yordayıcı rolünün olduğu görülmüştür (Marquart-Pyatt, McCright, Dietz ve Dunlap, 2014; Stanley, Wilson ve Milfont, 2017). Çalışma bulgularına göre sağcı bireyler; sorunun varlığını reddetme (Gifford ve Nilsson, 2014; McCright ve Dunlap, 2011), önemini küçümseme (Feygina, Jost ve Goldsmith, 2010), insan davranışlarının sorunun ortaya çıkmasındaki rolünü ve sorumluluğunu kabul etmeme (Campbell ve Kay, 2014) eğilimleri gösterirken solcu bireyler bu eğilimleri daha az sergilemektedirler (Gifford ve Nilsson, 2014; Hamilton ve ark., 2015). Farklı ideolojik yönelime sahip bireylerdeki özellikle iklim değişikliği konusu üzerinde şekillenen bu farklılaşma değişen düzeylerde de olsa ABD'de cumhuriyetçiler ve demokratlar arasında (Dunlap, McCright ve Yarosh, 2016), İngiltere'de United Kingdom Independence Party ve Liberal Democrat Party taraftarları arasında da gözlemlenmektedir (Fisher, Fitzgerald ve Poortinga, 2018).

Campbell ve Kay (2014) yukarıda kısaca özetlenen farklı bilimsel olguların ideolojilerin etkisiyle reddedilmesi üzerine yapılan araştırmalardan yola çıkarak (McCright ve Dunlap, 2011; Pew Research Center, 2010) var olan bir sorun için öne sürülen çözüm yönteminin o sorunu kabul etme üzerindeki etkilerine odaklanan bir dizi çalışma gerçekleştirmiştir. Araştırmacılar, ilk çalışmalarında iklim değişikliğinin varlığına yönelik şüpheciliğin bireylerin destekledikleri siyasi partilerin sunulan çözüm yöntemiyle uyuşan ve uyuşmayan politikalara sahip olmasıyla ilişkili olabileceği yönündeki hipotezi sınamışlardır. Çalışmada katılımcıların iklim değişikliği konusundaki bilimsel araştırmalara ve iklim değişikliğine yönelik çözüm önerilerinin ekonomiye olan etkilerine ilişkin görüşleri alınmıştır. Ayrıca serbest piyasa ekonomisi hakkındaki görüşlerinin sorunun varlığına yönelik şüphecilikleri ile ilişkisi ölçülmüştür. İlk çalışmanın bulguları iklim değişikliğine yönelik çözüm önerisi türleri hakkındaki görüşlerin, farklı politik grupları (Demokratlar ve Cumhuriyetçiler) benimsemekle ve bu grupların sorunun çözümü hakkındaki politikalarıyla ilişkili olduğunu göstermiştir. Cumhuriyetçilerin demokratlarla k1yaslandığında iklim değişikliği bilimi hakkında daha fazla şüpheci oldukları 
tespit edilmiştir. Ayrıca cumhuriyetçilerin iklim değişikliğine yönelik çözüm önerilerini daha fazla ekonomiyi tehdit edici gördükleri bulunmuştur. Aynı zamanda cumhuriyetçilerin iklim değişikliği politikaları bağlamındaki ekonomi ile ilgili görüşlerinin iklim değişikliği bilimine yönelik şüphe üzerinde aracı bir role sahip olduğu görülmüştür. İkinci çalışmada ise ilk çalışmadaki cumhuriyetçilerin iklim değişikliği bilimine yönelik şüphelerinin iklim değişikliği sorununu aşmak için önerilen çözüm politikaları ile ilişkili olduğu yönündeki korelasyonel bulgular deneysel olarak test edilmiştir. Bu amaçla katılımcıların yarısına cumhuriyetçilerin politikalarıyla oldukça çelişen bir çözüm önerisi okutulmuştur. Diğer yarısına ise iki tarafın da politikalarıyla uyumlu olan bir çözüm önerisi okutulmuştur. Sonuç olarak; cumhuriyetçilerin, kendi politikalarıyla uyumlu çözüm önerisi belirgin hâle getirildiğinde iklim değişikliği hakkında daha az şüpheci oldukları görülmüştür. Yani ilk ça1ışmadaki korelasyona dayalı bulgular deneysel bir çalışma ile de desteklenmiştir. Bunun ardından araştırmacılar çalışmalarının üçüncü adımı olarak çevre kirliliğinin sağlığa etkileri gibi iklim değişikliğinden farklı başka problemler üzerinden önceki çalışmaların sonuçlarını sınamış, ideolojilerin iklim değişikliğine özgü spesifik özelliklerinin etkisini de kontrol etmişlerdir. Ayrıca ideolojik görüşlerin siyasî partiye olan bağl1l1ktan bağımsız olarak serbest piyasa ekonomisi gibi belirli ideolojik bakış açıları ile iklim değişikliğini reddedici görüşler arasındaki ilişki incelenmiştir. Bilimsel olarak ortaya konmuş bir sorunun varlığını reddetmenin o soruna yönelik çözüm önerisi ve belirli bir siyasi parti aidiyetinden bağımsız olarak ideolojik düşünce ile ilişkili olduğu tespit edilmiştir. Dördüncü çalışmada ise yalnızca cumhuriyetçilerde değil demokratlarda da ideolojileri ile çelişen çözüm önerisi tiplerinin bireylerin kendi dünya görüşlerini tehdit edici özelliği nedeniyle sorunun varlığını reddedici davranışlara yol açtığı gözlemlenmiştir.

Sonuç olarak Campbell ve Kay (2014) tarafindan gerçekleştirilen çalışmalara göre bilimsel açıdan gerçekliği ortaya konmuş olan ve tüm insanları ilgilendiren bir problemin çözümü için öne sürülen yöntemin bireyler tarafından hoşnut görülüp görülmemesi, o sorunun varlığının kabul edilme düzeylerinde anlamlı bir farklılaşmaya neden olmaktadır. Ayrıca bu tepkiler bireylerin ideolojileriyle tutarlı olarak sunulan çözüm önerisinin kendi dünya görüşlerini tehdit edip etmediğine göre şekillenmektedir.

Bu çalışmada, Campbell ve Kay'in (2014) araştırmasının sonuçlarından yola çıkılarak Türkiye'nin uzun yıllara yayılmış ve sonuçları itibariyle en 
önemli sorunlarından biri hâline gelmiş olan Kürt sorununa odaklanılmıştır. Geçmişte yapılan birçok araştırmada soruna ilişkin farklı çözüm önerilerine ve Kürtlerin taleplerine karşı toplumda ciddi tepkilerin ortaya çıtığı görülmüştür (Dixon ve Ergin, 2010; Günes, 2012; Keyman, 2012; KONDA, 2011). Öte yandan farklı grupların birbirlerinin varlı̆̆ını kabul etmesi, onların sorunlarını anlaması toplumsal uzlaşının en temel şartlarındandır. Dolayısıyla Kürt sorununun varlığının kabul edilmesi ya da reddedilmesi süreçlerinin altında yatan psikolojik süreçleri anlamak oldukça önemlidir.

Buradan hareketle, araştırmada Kürt sorununa yönelik toplumda özellikle de Kürt olmayanların genelinde itici olarak görülen (örn., anadilde eğitim, özerklik) ve kabul edilebilir (örn. Türk kimliğinde birleşmek) görülen çözüm önerilerinin Kürt sorununun varlığını kabul etme veya reddetme üzerine olası etkileri araştırılmıştır. Yukarıda kısaca değinilen alanyazın ve çözüm hoşnutsuzluğu hipotezinden hareketle; bu araştırmada Kürt sorununa ilişkin itici çözüm önerisine maruz kalmanın kabul edilebilir çözüm önerisi ve kontrol koşuluna kıyasla Kürt sorununun varlığını daha az kabul etmeye neden olacağı hipotezi test edilmiştir. Ayrıca bireylerin etnik köken, ideoloji, milliyetçilik ve dindarlık açısından farklılaşmalarının Kürt sorununun varlığını kabul etme düzeylerinde etkili olacağ 1 öngörülmüştür.

\section{Yöntem}

\section{Çalışma Grubu}

Örneklem Başkent Üniversitesi ve Orta Doğu Teknik Üniversitesinde öğrenimine devam eden ve araştırmaya ilave ders notu karşılı̆̆ında katılan 245 (210 kadın; Ort. yaş $=20.73, \mathrm{SS}=1.58$ ) öğrenciden oluşmuştur. G*Power (Faul, Erdfelder, Lang ve Buchner, 2009) programı kullanılarak, bu örneklem büyüklügünün üç gruplu ve tek yönlü ANOVA için yeterli olduğu, küçük bir etki büyüklügünü ( $\mathrm{f}=.20) \% 80$ istatistikî güçle tespit etme olasılığına sahip olduğu görülmüştür.

\section{Veri Toplama Araçları}

\section{Çözüm Hoşnutsuzluğu Manipülasyonu}

Araştırmanın ilk bölümünde, katılımcılar rastgele bir şekilde üç gruba ayrılmıştır. İlk gruba ( $\mathrm{n}=81)$, "Kürt sorununun çözüm yolunun Kürtlerin yoğunlukta yaşadığı bölgelere özerklik verilmesinden geçtiği”" şeklindeki itici olacağ1 varsayılan bir çözüm önerisi sunulmuştur. İkinci gruba $(\mathrm{n}=82)$, çözümün "Kürtlerin anayasadaki Türkiye Cumhuriyeti vatandaşı anlamına gelen Türklükle kendilerini özdeşleştirmelerinden geçtiği” iddiasını içeren 
toplumun geneli için daha kabul edilebilir bir çözüm önerisi sunulmuştur. Üçüncü grup $(n=82)$ ise kontrol grubudur ve bu koşulda herhangi bir çözüm önerisi sunulmamıştır. Tüm gruplardaki katılımcılar sonrasında şu soruya cevap vermişlerdir: "Sizin kişisel fikrinize göre, Türkiye'de bir Kürt sorunu var mıdır? Lütfen aşağıdaki cevaplama formatını kullanarak kendi cevabınızı veriniz." (1=kesinlikle yoktur, 7=kesinlikle vardır).

\section{Demografik Bilgiler ve Genel Tutumlar}

Katılımcılar cinsiyetlerini, yaşlarını, ideolojilerini ( $1=$ aşırı solcu, 7=aşırı sağc1), milliyetçilik (1=hiç milliyetçi değilim, 7=fazlasıyla milliyetçiyim) ve dindarlık seviyeleri (1=hiç dindar değilim, 7=fazlasıyla dindarım) ile etnik kökenlerini (1=Türk, $2=$ Kürt, $3=$ Diğer, $4=$ Cevap vermek istemiyorum) birer madde ile belirtmişlerdir. Kullanılan anket bataryasının bir kopyasına internet üzerinden erişilebilmektedir (https://osf.io/3gnx9/?view_only=19fd18778cb34085affdfd4024321a76).

\section{Veri Toplanması ve Analizi}

Verilerin toplanması için katılımcılar çevrimiçi ankete yönlendirilmiştir. Bilgilendirilmiş onam formunun sunulmasının ardından araştırmaya gönüllü olarak katılmayı kabul eden bireylerden veri toplanmıştır. Katılımcılar yaş ve cinsiyetlerini belirttikten sonra manipülasyon materyalini tamamlamış, sonrasında ise genel tutum ölçen maddelere cevap vermişlerdir. Çalışmanın verisi toplanmaya başlamadan önce hipotez, çalışma tasarımı ve analiz planı önkayıt (preregistration) işlemiyle kaydedilmiş; çalışmanın verisi ve kullanılan veri toplama araçları da çevrimiçi ortamda paylaşılmıştır ${ }^{2}$. Araştırmanın sonunda katılımcılara geri bildirim verilerek araştırmanın amacı açıklanmıştır.

\section{Bulgular}

Araştırma deseninde yer alan ideolojik yönelim, milliyetçilik ve dindarlık değişkenleri arasındaki korelasyonlar Tablo 1'de görülebilir. Yürütülen Pearson Momentler Çarpımı Korelasyon analizi sonuçlarına göre ideolojik yönelimin milliyetçilik $(\mathrm{r}=.37, p<.001)$ ve dindarlık $(\mathrm{r}=.58, p<.001)$ değişkenleri ile pozitif yönde istatistiksel olarak anlamlı ilişkiye sahip olduğu tespit edilmiştir. Ayrıca milliyetçilik ile dindarlık $(\mathrm{r}=.54, p<.001)$ arasında da pozitif yönde istatistiksel olarak anlamlı ilişki olduğu görülmüştür.

\footnotetext{
2 Önkayılt formu (https://osf.io/jye8z/register/565fb3678c5e4a66b5582f67), veri ve veri toplama araçlarını barındıran proje sayfası (https://osf.io/3gnx9/?view_only=19fd18778cb34085affdfd4024321a76) ilgili linklerden ulaşılabilir durumdadır.
} 
Tablo 1. Korelasyon Analizi Sonuçları

\begin{tabular}{lcccccc}
\hline \multicolumn{1}{c}{} & 1 & 2 & 3 & 4 & 5 & 6 \\
\hline 1. İdeoloji & - & & & & & \\
2. Milliyetçilik & $.37^{* *}$ & - & & & & \\
3. Dindarlık & $.58^{* *}$ & $.54^{* *}$ & - & & & \\
4. Hoşnutsuzluk & -.08 & -.03 & -.07 & - & & \\
5. Sempatiklik & $-.22^{*}$ & .08 & -.14 & $\mathrm{~S}$ & - & \\
6. Kontrol & -.09 & .13 & .12 & $\mathrm{~S}$ & $\mathrm{~S}$ & - \\
$\quad$ Ort. & 3.51 & 4.04 & 3.50 & 4.67 & 4.62 & 4.32 \\
\multicolumn{1}{c}{$\boldsymbol{S S}$} & 1.20 & 1.70 & 1.78 & 1.90 & 1.80 & 1.91 \\
\hline
\end{tabular}

Not. $N=245$, s=sabit koşul, $* * *<.001, * p<.05$

\section{Çözüm Hoşnutsuzluğunun Sorunun Varlığını Kabul Etme Üzerine Etkisi}

ANOVA testi sonucunda; itici (Ort. $=4.67, \mathrm{~S}=1.90$ ), kabul edilebilir (Ort. $=4.62, \mathrm{~S}=1.80)$ ve kontrol grupları (Ort. $=4.32, \mathrm{~S}=1.91)$ arasinda anlamlı bir farklılaşma görülmemiştir, $\mathrm{F}(2.242)=.85, p=.431$. Sadece etnik kökeni Türk olan katılımcılar $(\mathrm{n}=204)$ incelendiğinde de benzer şekilde manipülasyonun etkisinin anlamlı seviyede olmadığı tespit edilmiştir, $\mathrm{F}(2.201)=.69, p=.504$.

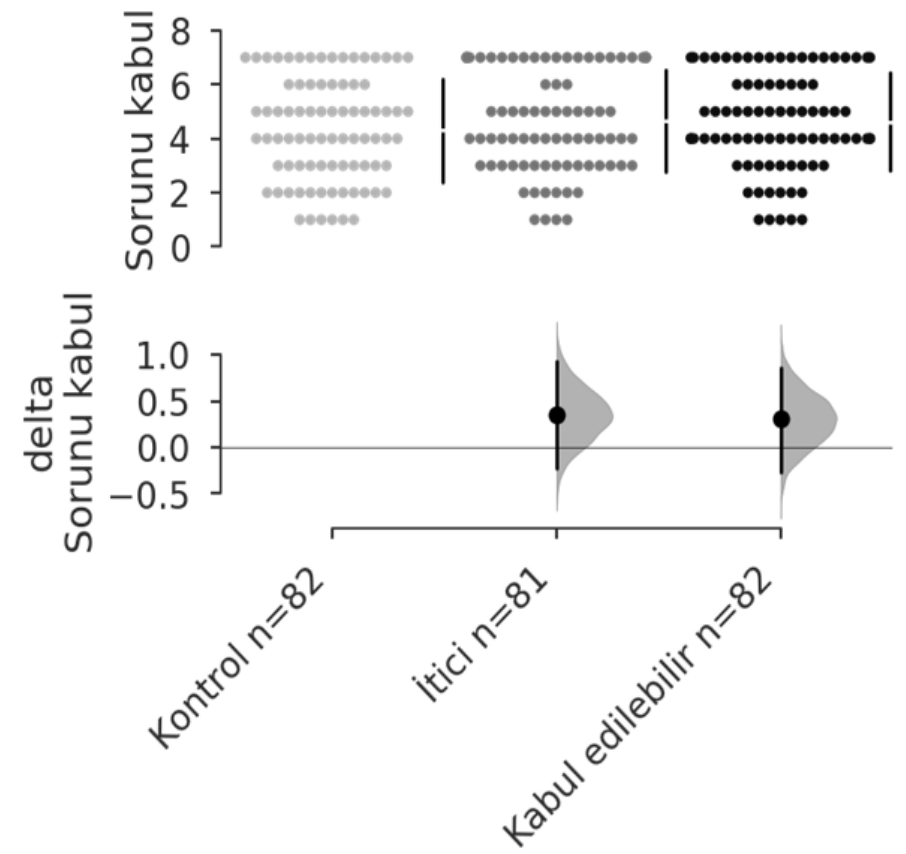

Şekil 1. Manipülasyonun Bağımlı Değişken Üzerindeki Etkisi 
Manipülasyon etki etmediği için, tüm koşullar birleştirilmiştir. Sonuçlar daha solcu olanların sorunun varlığını daha fazla kabul ettiklerini göstermiştir, $\mathrm{r}(243)=-.13, p=.046$. Ancak milliyetçilik, $\mathrm{r}(243)=.06, p=.343$ ve dindarlığın, $\mathrm{r}(243)=-.04, p=.561$, sorunun varlığını kabul ile ilişkili olmadığı bulunmuştur. ANOVA testi sonuçları Şekil 1'de görülebilir.

\section{Olası Etkileşimlerin İncelendiği Keşif Analizleri}

Yukarıda sunulan ve önkayıt formuyla uyumlu olan ana bulgulara ek olarak, ideoloji, milliyetçilik ve dindarlığın manipülasyonun etkisini düzenleyici rolü olup olmadığ ile yürütülen düzenlenmiş regresyon analizleri ile (Hayes, 2013) itici ve kabul edilebilir çözüm önerilerinin sunulduğu gruplar karşılaştırıldığında ne ideolojinin, $\mathrm{b}=-.21, \mathrm{SH}=.24, \mathrm{t}=-.90, p=.368$, ne de milliyetçiliğin, $\mathrm{b}=.11, \mathrm{SH}=.17$, $\mathrm{t}=.62, p=.535$, ne de dindarlığın, $\mathrm{b}=-.06, \mathrm{SH}=.16, \mathrm{t}=-.40, p=.693$, çözüm hoşnutsuzluğu manipülasyonu ile etkileşimi anlamlı bulunmuştur. Yürütülebilecek diğer olası keşif çalışmaları için kullanılan veri seti proje sayfasında erişilebilir durumdadır.

\section{Tartışma}

Araştırma bulguları genel olarak incelendiğinde Kürt sorunu için öne sürülen farklı çözüm önerilerinin bireyler tarafından itici olarak görülüp görülmemesinin sorunun varlığını kabul etme üzerinde bir etki yaratmadığı görülmektedir. Siyasî görüşleri açısından sol ve sağ skalasında farklılaşan katılımcılar kıyaslandığında ise daha solcu bireylerin Kürt sorununun varlığını daha fazla kabul ettikleri bulunmuştur. Ayrıca bireylerin milliyetçilik ve dindarlık düzeylerinin bu ilişkide anlamlı bir etkisinin olmadığı tespit edilmiştir.

$\mathrm{Bu}$ bulgular, toplumdaki çeşitli kesimler tarafından radikal görülen talep ve çözüm önerilerinin (örn., anadilde eğitim, yerel özerklik; Dixon ve Ergin, 2010; Günes, 2012; Keyman, 2012; KONDA, 2011) tek başlarına Kürt sorununun varlığını reddetmeye yol açmadığını göstermektedir. Başka bir deyişle, yalnızca çözüm yönteminin kabul edilir olup olmadığından hareketle Kürt sorununun varlığını reddetme etkisi ortaya çıkmamaktadır. Bu durum, Kürt sorununun pek çok farklı dinamikten beslenen, uzun yıllardır süren ve Türkiye'de yaşamın birçok alanına sirayet etmiş oldukça karmaşık bir yapıya sahip olmasıyla ilgili olabilir. Dolayısıyla Kürt sorununun varlığını reddedici tutum ve davranışların daha doğru bir biçimde tahlil edilebilmesinde çözüm önerisinin iticiliğine ek olarak başka birçok unsurun birlikte değerlendirildiği çok yönlü bir yaklaşımın benimsenmesi daha doğru olacaktır. 
Sonuçlar ideolojik yönelim açısından değerlendirildiğinde solcu bireylerin sorunun varlığını daha fazla kabul ettikleri görülmektedir. Bu bulgu alanyazındaki çözüm hoşnutsuzluğu araştırmasının çıkış noktasını oluşturan bilimsel gerçeklerin reddedilmesi üzerine yapılan araştırmalarla (Dunlap ve ark., 2016; Fisher, Fitzgerald ve Poortinga, 2018; Gifford ve Nilsson, 2014; Hamilton ve ark., 2015) tutarlı yöndedir. Ayrıca etnik kimliğiyle özdeşleşme düzeyi yüksek olan Türklerin, Kürtlere yönelik bireysel ve kolektif ayrımcıllı̆ı daha az algılama eğiliminde oldukları da bilinmektedir (Şen, 2017). Dolay1sıyla Türk kimliğiyle özdeşimi daha yüksek olduğu düşünülen sağcı bireylerin Kürt sorununun varlığını daha az kabul etmeleri çözüm önerisinin içeriğinden bağımsız olarak gruplar arası ilişkiler bağlamındaki kendi konum alışları çerçevesinde de şekilleniyor olabilir. Bir başka belirleyici etken ise insanların Kürt sorununun sonuçlarından etkilenme düzeyleriyle ilişkili olabilir. Campbell ve Kay (2014) tarafından gerçekleştirilen çözüm hoşnutsuzluğu araştırmasında ve onun öncülü olan bilimsel bulguların reddi üzerine olan çalışmalarda değerlendirmeye alınan sorun temaları genellikle insanların hayatını daha dolaylı olarak etkileyen unsurlardır. Öte yandan Kürt sorunu, güncel olarak insanların hayatını hem doğrudan hem de dolaylı olarak etkilemeye devam etmektedir. Şen'in (2017) araştırmasında da Kürt sorunu bağlamındaki çatışmalardan etkilenme düzeyinin bireysel ve kolektif ayrımcılığı algılama düzeyini yordadığı tespit edilmiş̧ir. Dolayısıyla bu bulgu da sorunun pek çok dinamikten etkilenen karmaşık bir yapı ile insanın tutum ve davranışlarına etki ettiği fikriyle paraleldir.

Milliyetçilik ve dindarlık düzeylerinin sorunun varlığını reddetme üzerinde anlamlı bir etkiye sahip olmaması ise ilginç bir bulgudur. Bu durum çoğunlukla batı örneklemlerinde gerçekleştirilen sol-sağ ayrımına dayalı siyaset psikolojisi alanyazınından farklılık göstermektedir (örn., Jost, Nosek ve Gosling, 2008). Alanyazında dindarlık ve milliyetçilik genellikle sağcılıkla daha çok ilişkili değişkenler olarak ele alınmaktadır. Bu çalışmada da ideolojik yönelim ile milliyetçilik ve dindarlık arasında pozitif yönlü korelasyon tespit edilmiştir. Yani ideolojik yönelim soldan sağa gittikçe milliyetçilik ve dindarlık düzeyleri artış göstermektedir. Fakat ideolojik yönelimin sorunu kabul etmeye etkisi görülürken ideoloji değişkeniyle ilişkisi güçlü olan milliyetçilik ve dindarlık düzeylerinin etkisi bulunamamıştır. Bu durum Türkiye'deki politik akımların ve siyasi merkezlerin kendi tarihsellikleri, özgünlükleri ve batıyla kıyaslandığında daha farklı süreçlerin etkisiyle şekillenmeleri açısından düşünüldüğünde daha iyi anlaşılabilir. Türkiye'de dindarlık ve milliyetçilik 
yalnızca să̆ görüşlerle değil aynı zamanda sol görüşlerle de ilişkili olarak görülebilmektedir. Örneğin, Yılmaz, Sarıbay, Bahçekapılı ve Harma'nın (2016) yaptıkları çalışmada Türkiye'de sosyal demokrasiyi temsil eden ana parti olan Cumhuriyet Halk Partisi'ne oy vereceğini beyan eden katılımcılar ahlakî görüşleri açısından (örneğin gruba sadakat) merkez sağ 1 ve milliyetçiliği temsil eden Milliyetçi Hareket Partisi ve Adalet ve Kalkınma Partisi'ne oy vereceğini beyan eden katılımcılardan farklılaşmamışlardır. Dolayısıyla Kürt sorunu gibi Türkiye'ye özgü spesifik bir sorunsalın anlaşılmasında ideoloji ve onunla ilişkili olan çeşitli motivasyonların rolünü değerlendirirken ideolojilerin ve siyasi grupların da Türkiye’ye özgü nitelikleri göz önünde bulundurulmalıdır.

Tüm bunların yanı sıra araştırmanın çeşitli kısıtlı1ıkları da mevcuttur. Çalışmanın önemli kısıtlılıklarından bir tanesi sorunu dile getiren öznenin özellikleriyle ilgilidir. Çözüm hoşnutsuzluğu ya da bilimsel olguların reddi üzerine yapılan çalışmalarda sorunun var olduğunu iddia eden kesim toplumsal yapıda gücü elinde bulunduran, yüksek statülü bireylerden (örn., bilim insanı) oluşmaktadır (Campbell ve Kay, 2014). Bu çalışmada da benzer şekilde manipülasyon sırasında bir bilim insanının sözleri kullanılmıştır. Fakat Kürt sorununun varlığı genellikle güvenilirliği pek çok farklı düzeyde olan ve statüleri açısından birbirinden farklılıklar gösterebilen gruplar ya da kişiler tarafından dile getirilmektedir. Dolayısıyla bu çalışmada benzer sonuçların gözlenememiş olması genellikle toplumda Kürt sorununa yönelik çözüm önerisini sunan mesajın kaynağının statü açısından birbirinden farklı niteliklere sahip olmasından kaynaklanmış olabilir. Gelecekte yapılacak araştırmalarda süreç içinde potansiyel olarak etkisi olabilecek çözümü öne süren öznenin statüsü de bir değişken olarak göz önünde bulundurulmalıdır.

Öte yandan, bu araştırmada farklı bulgular elde edilmiş olmasının bir başka nedeni Campbell ve Kay (2014)'in çalışmasında ele alınan sorun ile bu çalışmadaki sorunun farklı değerlendirme süreçlerinin ardından ortaya konması olabilir. İklim değişikliği sorunu bilimsel yöntemler ile tespit edilen objektif bir sorunsalken Kürt sorunu insanlar arasında daha sübjektif değerlendirme süreçleri ve kişisel deneyimler aracıllğıyla varlığına inanılan bir problemdir. Her ne kadar Kürt sorunu tarihsel açıdan çok uzun süredir gündemde olan bir konu olsa da bu sübjektiflik, sonuçlar üzerinde karıştırıcı bir etki yaratıyor olabilir. Dolayısıyla katılımcıların bir kısmı çözüm yönteminin ne olduğundan bağımsız olarak böyle bir sorunun gerçekten var olduğuna veya var olmadığına dair katı subjektif yorumları çerçevesinde hareket etmiş olabilir. 


\section{Sonuç}

Araştırma sonuçları Kürt sorununun çözümüne yönelik müdahalelerin sorunun kendisi kadar karmaşık ve çok boyutlu bir yapıya sahip olması gerektiğine işaret etmektedir. Çünkü bu araştırmanın sonuçlarına göre gündelik hayatta sanıldığ gibi sorunun çözüm yöntemini oluşturan talepler, insanlar üzerinde beklenen olumlu veya olumsuz etkileri yaratamayabilmektedir. Sunulan bulgular hem kuramsal olarak alanyazına katkı sağlamakta ve Kürt sorunu üzerine yapılabilecek gelecek araştırmaların önünü açmakta hem de sorunun çözümü için rol oynayabilecek aktörlere bilgilendirici bir kaynak oluşturmaktadır. Söz konusu sonuçlar, pratikte varsayılanın (Dixon ve Ergin, 2010; Günes, 2012; Keyman, 2012; KONDA, 2011) aksine sunulan farklı çözüm önerilerinin insanların kemikleşmiş tutumlarını etkileyecek düzeyde etkili olmadığını ve bu tutumların değişmesi için çok daha kapsamlı bir perspektif edinilmesi gerektiğiyle ilgili ön bulgular sağlamaktadır. Gelecek çalışmaların, çözüm yöntemi ve Kürt sorununun kabulü arasındaki ilişkiyi farklı değişkenleri de hesaba katarak incelemesi gerektiği değerlendirilmektedir.

$\mathrm{Bu}$ çalışmada Kürt sorununun çözümünün önündeki güncel engellerden biri olarak düşünülen toplumun çeşitli kesimlerindeki sorunun varlığını reddedici tutum ve davranışların beslendiği dinamiklerin daha iyi anlaşılması ve bu engeli ortadan kaldırabilecek uygulamaların geliştirilmesine katkılar sunulması hedeflenmiştir. Bu çaba, birçok ülkede farklı sorunlar çerçevesinde ortaya çıkmış olan gruplar arası çatışmaları sonlandırmaya yönelik barış ve müzakere denemelerinin başarısız olduğu gerçeği düşünüldügünde oldukça kıymetli fakat yetersizdir. Kürt sorununa ilişkin bugüne kadar birçok farklı alanda (ekonomi, siyaset, sosyoloji vb.) araştırmalar yürütülmüş olmasına rağmen psikolojik değişkenlerin bu konuya olası etkileri sınırlı düzeyde ele alınmıştır. Gerçekleştirilecek yeni araştırmalarla Kürt sorununa yönelik farklı bakış açılarını besleyen psikolojik değişkenlerin keşfedilmesi; sorunun ortadan kaldırılması ve toplumsal refahın arttırılması için uygulanabilecek politikaların belirlenmesine önemli bilgiler sunarak hizmet edecektir.

\section{Kaynakça}

Arkonaç, S. A., Tekdemir, G. ve Çoker, Y. Ç. (2012). "Kürt sorununu" açıklamada kişisel duruş inşası ve mesafe alışlar. Elektronik Sosyal Bilimler Dergisi, $11(39), 251-261$.

Balaban, Ç. D. (2013). The roles of intergroup threat, social dominance orientation and right-wing authoritarianism in predicting Turks' prejudice toward Kurds. Yayınlanmamış yüksek lisans tezi, Orta Doğu Teknik Üniversitesi Sosyal Bilimler Enstitüsü. 
Bayad, A. (2015). Türkiyeli Kürtlerin etnik kimlik statülerinde yaşanan farklılaşmanın değer aktarım süreçleriyle olan ilişkisinin incelenmesi. Yayınlanmamış yüksek lisans tezi, İstanbul Üniversitesi Sosyal Bilimler Enstitüsü.

Baysu, G., Coşkan, C. ve Duman, Y. (2018). Can identification as muslim increase support for reconciliation? The case of the Kurdish conflict in Turkey. International Journal of Intercultural Relations, 64, 43-53.

Campbell, T. H. ve Kay, A. C. (2014). Solution aversion: On the relation between ideology and motivated disbelief. Journal of Personality and Social Psychology, 107(5), 809-824.

Doi: $10.1037 / \mathrm{a} 0037963$

Carrus, G., Panno, A. ve Leone, L. (2018). The moderating role of interest in politics on the relations between conservative political orientation and denial of climate change. Society \& Natural Resources, 31(10), 1103-1117.

Cingöz-Ulu, B. (2008). Structure of Turkish national identity and attitudes toward ethno-cultural groups in Turkey. Yayınlanmamıs doktora tezi, York University Faculty of Graduate Studies.

Clayton, S., Koehn, A. ve Grover, E. (2013). Making sense of the senseless: Identity, justice, and the framing of environmental crises. Social Justice Research, 26(3), 301-319.

Çelebi, E., Verkuyten, M., Köse, T. ve Maliepaard, M. (2014). Out-group trust and conflict understandings: The perspective of Turks and Kurds in Turkey. International Journal of Intercultural Relations, 40, 64-75.

Çoksan, S. (2016). Sosyal kimlik özdeşimi ve iç grup normunun iç grup yanlılığ ile ilişkisi. Yayınlanmamış yüksek lisans tezi, Mersin Üniversitesi Sosyal Bilimler Enstitüsü.

Dixon, J. C. ve Ergin, M. (2010). Explaining anti-kurdish beliefs in Turkey: Group competition, identity, and globalization. Social Science Quarterly, 91(5), 1329-1348.

Doi: $10.1111 / j .1540-6237.2010 .00734 . x$

Druckman, J. N. ve McGrath, M. C. (2019). The evidence for motivated reasoning in climate change preference formation. Nature Climate Change, 9, 111-119.

Dunlap, R. E., McCright, A. M. ve Yarosh, J. H. (2016). The political divide on climate change: Partisan polarization widens in the US. Environment: Science and Policy for Sustainable Development, 58(5), 4-23.

Ergil, D. (2000). The Kurdish question in Turkey. Journal of Democracy, 11(3), 122135.

Ergin, M. (2014). The racialization of Kurdish identity in Turkey. Ethnic and Racial Studies, 37(2), 322-341.

Faul, F., Erdfelder, E., Buchner, A. ve Lang, A-G. (2009). Statistical power analyses using G*Power 3.1: Tests for correlation and regression analyses. Behavior Research Methods, 41, 1149-1160.

Doi: 10.3758/BRM.41.4.1149

Feinberg, M. ve Willer, R. (2011). Apocalypse soon? Dire messages reduce belief in global warming by contradicting just-world beliefs. Psychological Science, 22(1), 34-38.

Feygina, I., Jost, J. T. ve Goldsmith, R. E. (2010). System justification, the denial of 
global warming, and the possibility of "system-sanctioned change". Personality and Social Psychology Bulletin, 36(3), 326-338.

Fisher, S., Fitzgerald, R. ve Poortinga, W. (2018). Climate change social divisions in belief and behaviour. Phillips, D., Curtice, J., Phillips, M. ve Perry, J., (Ed.), British social attitudes: the $35^{\text {th }}$ report içinde (1-26). London: The National Centre for Social Research.

Fritsche, I., Cohrs, J. C., Kessler, T. ve Bauer, J. (2012). Global warming is breeding social conflict: The subtle impact of climate change threat on authoritarian tendencies. Journal of Environmental Psychology, 32(1), 1-10.

Gifford, R. ve Nilsson, A. (2014). Personal and social factors that influence proenvironmental concern and behaviour: A review. International Journal of Psychology, 49(3), 141-157.

Göregenli, M. (2010). Psikolojinin Kürt sorunuyla imtihanı. Eleştirel Psikoloji Bülteni, 3-4, 3-11.

Günes, C. (2012). Unblocking the impasse in Turkey's Kurdish question. Peace Review: A Journal of Social Justice, 24(4), 462-469.

Hamilton, L. C. (2015). Conservative and liberal views of science: Does trust depend on topic? (Regional Issue Brief No. 45). Durham, NH: University of New Hampshire.

Hamilton, L. C., Hartter, J., Lemcke-Stampone, M., Moore, D. W. ve Safford, T. G. (2015). Tracking public beliefs about anthropogenic climate change. PLoS ONE, 10(9), e0138208.

Doi: $10.1371 /$ journal.pone. 0138208

Hamilton, L. C., Hartter, J. and Saito, K. (2015). Trust in scientists on climate change and vaccines. SAGE Open, 5(3).

Doi: $10.1177 / 2158244015602752$

Häkkinen, K. ve Akrami, N. (2014). Ideology and climate change denial. Personality and Individual Differences, 70, 62-65.

Hayes, A. F. (2013). Introduction to mediation, moderation, and conditional process analysis: A regression-based approach. New York: Guildford Press.

Jessani, Z. ve Harris, P. B. (2018). Personality, politics, and denial: Tolerance of ambiguity, political orientation and disbelief in climate change. Personality and Individual Differences, 131, 121-123.

Jost, J. T., Nosek, B. A. ve Gosling, S. D. (2008). Ideology: Its resurgence in social, personality, and political psychology. Perspectives on Psychological Science, $3(2), 126-136$.

Keyman, E. F. (2012). Rethinking the 'Kurdish question' in Turkey: Modernity, citizenship and democracy. Philosophy \& Social Criticism, 38(4-5), 467-476. Doi: 10.1177/0191453711435655

Kirişçi, K. (2011). The Kurdish issue in Turkey: Limits of European Union reform. South European Society and Politics, 16(2), 335-349.

Doi: 10.1080/13608746.2011.577954

Kirişçi, K. ve Winrow, G. M. (2011). Kürt sorunu: kökeni ve gelişimi. (A. Fethi, Çev.). İstanbul: Tarih Vakfı Yurt Yayınları.

KONDA. (2011). Kürt meselesinde algı ve beklentiler araştırması. $\mathrm{http} / /$ konda.com.tr/tr/rapor/kurt-meselesinde-algi-ve-beklentiler

Leiserowitz, A., Maibach, E., Roser-Renouf, C., Feinberg, G. ve Rosenthal, S. (2015). 
Climate change in the American mind: October. New Haven, CT: Yale University and George Mason University.

http://environment.yale.edu/climate-communication-OFF/files/Climate-

Change-American-Mind-October-2015.pdf

Marquart-Pyatt, S. T., McCright, A. M., Dietz, T. ve Dunlap, R. E. (2014). Politics eclipses climate extremes for climate change perceptions. Global Environmental Change, 29, 246-257.

McCright, A. M. ve Dunlap, R. E. (2010). Anti-reflexivity. Theory, Culture \& Society, 27(2-3), 100-133.

Doi: $10.1177 / 0263276409356001$

McCright, A. M. ve Dunlap, R. E. (2011). Cool dudes: The denial of climate change among conservative white males in the United States. Global Environmental Change, 21, 1163-1172.

Meclis Araştırması Komisyonu Raporu. (2013). Terör ve şiddet olayları kapsamında yaşam hakk ihlallerini inceleme raporu. Ankara: TBMM Yayınları.

Metropoll. (2012). Türkiye siyasal durum araştırmast. http://metropoll.com.tr/arastirmalar/siyasi-arastirma-9/1714

Metropoll. (2013). Türkiye'nin nabzı 'yeni çözüm süreci'. http://www.metropoll.com.tr/upload/content/files/1730-turkiyenin-nabzinisan-2013.pdf

Pew Research Center. (2010). Wide partisan divide over global warming. http://www.pewresearch.org/2010/10/27/wide-partisan-divide-over-globalwarming

Saraçoğlu, C. (2009). İzmirli orta sınıfta Kürt algısı: mekân, sınıf ve kentsel yaşam. Praksis, 21, 17-46.

Seta ve Pollmark. (2009). Türkiye’nin Kürt sorunu algısı. http://file.setav.org/Files/Pdf/20130109171358 turkiyenin-kurt-sorunualgisi.pdf

Stanley, S. K., Wilson, M. S. ve Milfont, T. L. (2017). Exploring short-term longitudinal effects of right-wing authoritarianism and social dominance orientation on environmentalism. Personality and Individual Differences, 108, 174-177.

Şen, E. (2017). Algılanan ayrımcılık ve sosyal kimlik ilișkisi: Türk ve Kürt etnik grupları üzerine bir çalışma. Nesne Dergisi, 5(11), 449-468.

Tranter, B. ve Booth, K. (2015). Scepticism in a changing climate: A cross-national study. Global Environmental Change, 33, 154-164.

Uluğ, Ö. M. ve Cohrs, J. C. (2017). Examining the ethos of conflict by exploring lay people's representations of the Kurdish conflict in Turkey. Conflict Management and Peace Science, 36(2), 1-22.

Doi: $10.1177 / 0738894216674969$

Villellas, A. (2011). Turkey and the Kurdish question: Reflecting on peacebuilding. Quaderns de Construccio de Pau No. 22. Escola de Cultura de Pau. https://ddd.uab.cat/pub/quaconpau/quaconpau a2011m06n22iENG.pdf

Yeğen, M. (2009). "Prospective-Turks" or "Pseudo-Citizens:" Kurds in Turkey. The Middle East Journal, 63(4), 597-615.

Doi: $10.3751 / 63.4 .14$

Yeğen, M. (2012). Son Kürt isyanı. İstanbul: İletişim Yayınları. 
Y1ld1z, K. (2007). The Kurds in Iraq: Past, present and future. London: Pluto Press

Y1ldiz, K. (2012). Turkey's Kurdish conflict: pathways to progress. Insight Turkey, 14(4), 151-174.

Yılmaz, O., Cesur, S. ve Bayad, A. (2018). Türklerin ve Kürtlerin birbirlerine karş1 olumsuz tutumlarının bazı psikolojik değişkenlerle ilişkisi. Türk Psikoloji Yazllarl, 21, 82-99.

Yılmaz, O., Sarıbay, S. A., Bahçekapılı, H. G. ve Harma, M. (2016). Political orientations, ideological self-categorizations, party preferences, and moral foundations of young Turkish voters. Turkish Studies, 17(4), 544-566. 